\title{
A double-response paradigm to study stimulus intensity effects upon the motor system in simple reaction time experiments
}

\author{
ROLF ULRICH and KURT H. STAPF \\ University of Tubingen, Tubingen, Federal Republic of Germany
}

\begin{abstract}
A double response paradigm is utilized to study stimulus intensity effects upon the motor system in simple visual and auditory reaction times (RT). Subjects had to respond with both hands simultaneously upon detection of a stimulus. The RT difference of both hands is thereby of special interest, because it is considered that this variable does not contain any sensory latency and therefore allows one to study those processes that follow stimulus detection. It was found that the RT-difference distribution varies with stimulus intensity, which questions the general view that stimulus intensity affects only very early sensory stages in the processing chain. In particular, it was found that the variance of RT difference diminished with increasing stimulus intensity. This finding supports the notion of speeding up the motor process by increasing stimulus intensity. A generalization of a stochastic model by Meijers and Eijkman (1974) and Meijers, Teulings, and Eijkman (1976) is advanced to account for the findings. The central assumption is that more units (e.g., motoneurons) are activated if stimulus intensity is increased. The model's qualitative predictions are confirmed.
\end{abstract}

In a typical study of simple reaction time (RT), the subject is required to respond by keypressing as soon as possible after stimulus detection. A breakdown of the whole RT process in at least two successive stages is hereby often assumed. The first stage reflects processes that take place until a detection of the stimulus occurs. After detection of the stimulus, the motor system-the second stage-is activated for response execution. Within this framework, $\mathrm{RT}$ is considered to reflect the sum of times taken by each of the two stages.

Attempts to decompose the two stages date from the beginning of this century (Alechsieff, 1900; Fröhlich, 1929; Hazelhoff \& Wiersma, 1925a, 1925b, 1926; Vogelsang, 1925). Even today researchers are still interested in isolating the two processes, and numerous models about the detection process in simple RT exist. Three examples of special models about the detection process are: the timing model (Luce \& Green, 1972), the counting model (McGill, 1963), and the random-criterion model (Grice, 1968). To test the proposed detection process, authors are often constrained to make additional assumptions about the motor process too. Accordingly, the following two assumptions are often found in simple RT literature.

First, it is sometimes assumed that the variance of the motor delay $(\mathrm{M})$ makes only a small contribution to the

The authors gratefully acknowledge the constructive comments of Peter Day, Miles Hewstone, Christian Holubarsch, David Kohfeld, KlausPeter Muthig, Dirk Vorberg, and the editor. Some results presented here were reported at the 23. Tagung experimentell arbeitender Psychologen, Trier, 1982. Requests for reprints should be sent to Rolf Ulrich, Psychologisches Institut, Universität Tübingen, Friedrichstrasse 21, D7400 Tübingen, Federal Republic of Germany. whole RT variance (Kornblum, 1973; Meijers \& Eijkman, 1977). Although the motor delay is not directly measurable, some studies indirectly justify this assumption. In tapping experiments, a time keeper is assumed to trigger motor responses. The overt response occurs after a variable motor delay (Vorberg \& Hambuch, 1977; Wing \& Kristofferson, 1973). The variance of the motor delay is accordingly inferred by the covariance of adjacent interresponse times of finger taps. The estimated motor variance appears to be $10-20 \mathrm{msec}^{2}$.

Botwinick and Thompson (1966) decomposed simple RT into a premotor component and a motor one. Decomposition was based upon EMG onset and finger-lift response. EMGs were recorded from the extensor muscle of the responding forearm during measurement of simple auditory RT. The variance ratio of premotor time to motor time ranged from 5:1 to 10:1.

Gibbon and Rutschmann (1969) related simple RT distribution to temporal order judgments. In their perceptual latency model the temporal order of two stimuli is judged according to the order of corresponding sensations. A comparison of RT distribution and the psychometric function of the temporal order judgments suggested that the variance of the motor delay was very small relative to the variance of the perceptual latency. These different approaches support the notion that the variance contribution of the motor delay to the total RT variance is very small.

Second, in several studies the decrease of RT with stimulus intensity is explicitly attributed to a speeding up of the earliest stages of stimulus encoding (Burbeck \& Luce, 1982; Hildreth, 1979; Kohfeld, Santee, \& Wallace, 1981; Sternberg, 1969). Occasionally, stimulus intensity 
effects have been attributed entirely to retinal processes (Vaughan, Costa, \& Gilden, 1966). Nissen (1977) reviewed the physiological and behavioral literature regarding the effects of stimulus intensity on the time course of information processing. She concluded that not only is the processing in sensory pathways speeded up by stimulus intensity, but also alertness and the time taken to direct attention to a stimulus is affected by stimulus intensity. However, the fact that stimulus intensity might also affect very late stages in the processing chain is sometimes overlooked. Some studies support this possibility.

Hazelhoff and Wiersma (1926) compared simple visual RT and perceptual latency for three intensity levels. Perceptual latency was measured with the method of localization (Hazelhoff \& Wiersma, 1925a). In the localization method, a constant eye movement is needed. This is achieved by the subject's fixating a moving shadow above which a scale is installed. The subject is required to indicate on the scale where he sees a stimulus lighting up in the shadow. The perceptual latency is computed using the distance between the real and perceived stimulus positions and the speed of the moving shadow. Utilizing this method, Hazelhoff and Wiersma found that while perceptual latency decreased with intensity, so did the difference between RT and perceptual latency-suggesting that the motor delay was shorter when stimulus intensity was increased. The difference between the most intense and weakest stimulus appeared to be $33 \mathrm{msec}$.

Vogelsang (1925), using a slight modification of the localization method, did not find such a profound effect on the difference between RT and perceptual latency for the two intensity levels employed in his experiment. We reexamined the data of his subjects and found that the difference between RT and perception time for the weak stimuli was on average $10 \mathrm{msec}$ greater than it was for the intense stimulus. It might be that the two intensity levels in the Vogelsang study were not very different. This consideration is suggested if one compares the RTs for the weakest and the most intense stimuli in both studies: In the Hazelhoff and Wiersma study, the RTs at these extreme stimulus levels were significantly more different than they were in the Vogelsang study.

Roufs (1974) considered the perceptual latency to a test flash using three methods: double flash, eye and ear, and simple RT. He measured the course of perceptual latency as a function of intensity for the test flash over a large intensity range. In the eye-and-ear method (Exner, 1875), the onset of a tone and the test flash are shifted so far from each other to seem, subjectively, to start simultaneously. The same procedure is used in the double flash method, with one exception. Instead of the tone, a second flash serves as a reference for the simultaneity judgment. To be judged as simultaneous, the more intense the test flash, the later the test flash must start-that is, the perceptual latency is speeded up. If intensity affects only the perceptual latency of the test flash, then the shifts of the onset times must correspond to an equal RT decrease. Roufs found that, as a function of intensity, the course of RT was steeper than the corresponding shifts measured by the other two methods. This, however, is to be expected if later processes (e.g., the motor system) are also affected by stimulus intensity. The aim of this paper was to provide further evidence that the motor system in simple RT is speeded up for intense stimuli. Our experimental approach to this issue, however, was quite different from that of the studies reported above. Before going into greater experimental detail, we will describe the logical basis of our approach.

\section{THE DOUBLE-RESPONSE PARADIGM}

In our modified simple RT paradigm, the subject is required to respond to a stimulus with both hands simultaneously. Each hand is thereby separately timed from stimulus onset until response. The RTs for the right and left hands are $\mathrm{RT}_{\mathrm{R}}=\mathrm{S}+\mathrm{M}_{\mathrm{R}}$ and $\mathrm{RT}_{\mathrm{L}}=\mathrm{S}+\mathrm{M}_{\mathrm{L}}$, respectively (see Figure 1). The common component, $S$, in both RTs is the time needed to detect the stimulus and to prepare the motor command for movement execution. The overt responses of the right and left hands occur after variable motor delays, $\mathrm{M}_{\mathrm{R}}$ and $\mathrm{M}_{\mathrm{L}}$. Accordingly, on one trial, the response of the right hand might precede the response of left hand if $M_{R}$ is smaller than $M_{L}$, whereas, on other trials, the response of the left hand might precede the response of the right hand if $M_{L}$ is

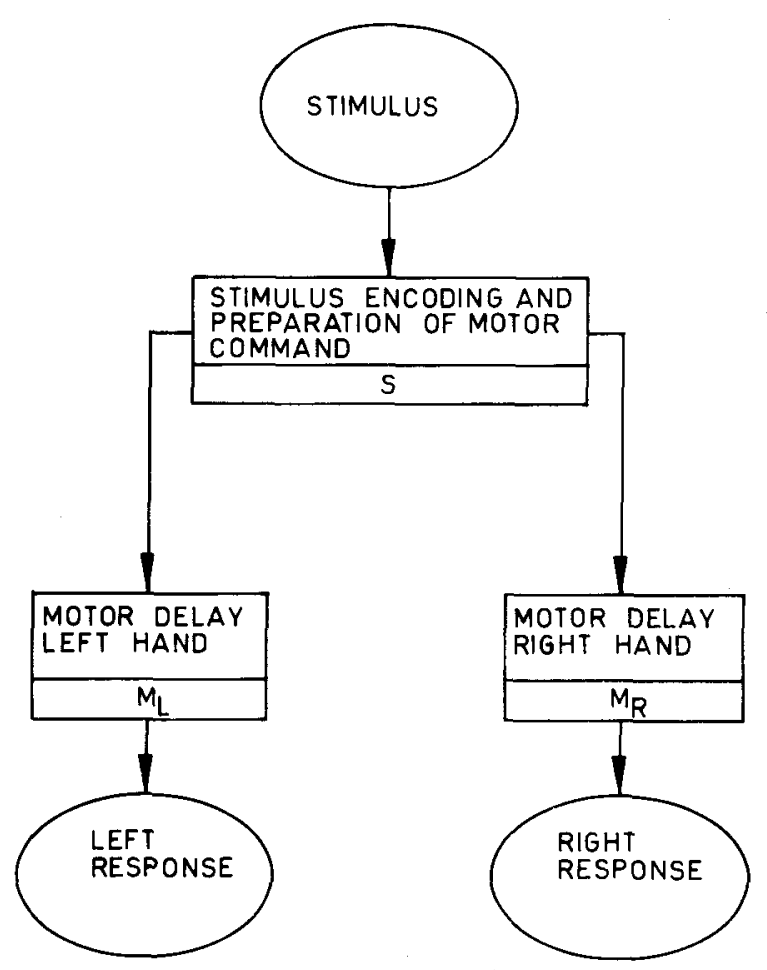

Figure 1. Structure underlying the double response paradigm. It is assumed that after stimulus detection a central motor command triggers the response execution for both hands simultaneously. After variable motor delays, the responses of the left and right hands occur. 
smaller than $M_{R}$. This trial-to-trial variation of $R T_{R}$ and $\mathrm{RT}_{\mathrm{L}}$ can be used to isolate the motor delays.

For each trial, we consider the difference of both RTs. This RT difference, $\mathrm{D}=\mathrm{RT}_{\mathbf{L}}-\mathrm{RT}_{\mathrm{R}}=\left(\mathrm{S}+\mathrm{M}_{\mathbf{L}}\right)-$ $\left(S+M_{R}\right)=M_{L}-M_{R}$, depends only on $M_{L}$ and $M_{R}$, since the common component $S$ is dropped, that is, D depends only on those stages that follow the central motor command. Therefore, if stimulus intensity affects only the earliest stages of stimulus encoding, then the distribution of the RT difference should be unaffected by a change in stimulus intensity. It should be noted that this can be tested without further assumptions concerning the distributions of $M_{L}$ and $M_{R}$, and without assuming that the mean motor delays are equal for both hands.

Within this paradigm, the variance of the motor delay can be isolated by considering the variance of the RT difference:

$$
\begin{aligned}
\operatorname{var}(\mathrm{D})= & \operatorname{var}\left(\mathrm{M}_{\mathbf{L}}-\mathrm{M}_{\mathbf{R}}\right) \\
= & \operatorname{var}\left(\mathrm{M}_{\mathrm{L}}\right)+\operatorname{var}\left(\mathrm{M}_{\mathbf{R}}\right) \\
& -2\left[\operatorname{corr}\left(\mathrm{M}_{\mathrm{L}}, \mathrm{M}_{\mathbf{R}}\right) \mathrm{SD}\left(\mathrm{M}_{\mathrm{L}}\right) \mathrm{SD}\left(\mathrm{M}_{\mathrm{R}}\right)\right],
\end{aligned}
$$

where $\operatorname{corr}\left(\mathrm{M}_{\mathrm{L}}, \mathrm{M}_{\mathrm{R}}\right)$ denotes the correlation between $\mathrm{M}_{\mathrm{L}}$ and $M_{R}$, and $S D\left(M_{L}\right)$ and $S D\left(M_{R}\right)$ are the standard deviations of $M_{L}$ and $M_{R}$, respectively.

We define an average motor delay variance

$$
\operatorname{var}(M)=\left[\operatorname{var}\left(M_{L}\right)+\operatorname{var}\left(M_{R}\right)\right] / 2
$$

and insert this definition into Equation 1. This yields

$$
\begin{aligned}
& \operatorname{var}\left(M_{L}-M_{R}\right) / 2 \\
& \quad=\operatorname{var}(M)+\operatorname{corr}\left(M_{L}, M_{R}\right) S D\left(M_{L}\right) S D\left(M_{R}\right),
\end{aligned}
$$

$\operatorname{var}(\mathbf{M})$

$$
=\operatorname{var}\left(\mathbf{M}_{\mathbf{L}}-\mathbf{M}_{\mathbf{R}}\right) / 2-\left[\operatorname{corr}\left(\mathbf{M}_{\mathbf{L}}, \mathbf{M}_{\mathbf{R}}\right) \operatorname{SD}\left(\mathrm{M}_{\mathbf{L}}\right) \mathbf{S D}\left(\mathbf{M}_{\mathbf{R}}\right)\right]
$$

Since motor responses in simple RT are ballistic movements without feedback loops for movement control (Denier van der Gon \& Thuring, 1965; Meijers \& Eijkman, 1974), $M_{L}$ and $M_{R}$ should not be substantially correlated. Therefore, Equation 2 reduces to:

$$
\operatorname{var}(\mathrm{M})=\operatorname{var}\left(\mathrm{RT}_{\mathrm{L}}-\mathrm{RT}_{\mathrm{R}}\right) / 2 .
$$

If the two motor delays $\mathbf{M}_{\mathbf{L}}$ and $\mathbf{M}_{\mathbf{R}}$ should correlate positively (negatively), Equation 3 underestimates (overestimates) the true value of $\operatorname{var}(\mathrm{M})$.

Some researchers (Bartlett \& White, 1965; Nakamura \& Saito, 1974; Nakamura, Taniguchi, \& Oshima, 1975) used this double response paradigm to study handedness and movement synchronization for voluntary and signal- triggered movements. In those studies, subjects had to respond with both hands upon the occurrence of a stimulus. Thus, the main variable of interest was RT difference for different stimulus conditions. Those authors also published the standard deviations of RT difference. If one applies Equation 3 to their published data, the obtained estimates of $\operatorname{var}(\mathbf{M})$ agree excellently with the corresponding estimates of the motor delay variance published in finger-tapping experiments (Vorberg \& Hambuch, 1977; Wing \& Kristofferson, 1973). Although our approach in the estimation of $\operatorname{var}(\mathbf{M})$ differs from that in the fingertapping experiments, both approaches lead to almost the same estimates.

To determine if stimulus intensity speeds up the motor delay, an inferential leap is needed, because one cannot observe the motor delay directly: Mean and variance of latencies are usually positively correlated (see, e.g., the exponential, gamma, Weibull, and Gumbel distributions). Therefore, if the variance of the motor delay (computed via Equation 3) decreases with stimulus intensity, this gives evidence that mean motor delay is decreased too, although mean motor delay is not directly observable.

There is also empirical evidence that mean and variance of latencies in the nervous system are positively correlated. Levick (1973) investigated the latency of a cat's retinal ganglion cell to brief flash stimuli of different intensities. With increasing intensity, the mean and the variance of this latency decreased. We will outline in a later theoretical section a physiologically motivated model of the motor delay. This model predicts that with increasing stimulus intensity, mean and variance of the motor delay will decrease.

\section{EXPERIMENT 1}

Experiment 1 was designed to assess whether stimulus intensity of a tone would affect the distribution of RT difference and whether the variance of the motor delay would decrease with increasing stimulus intensity.

\section{Method}

Subjects. Four right-handed subjects, G.U., T.H., K.M., and R.U. (students and staff members of our psychology department, and all without hearing problems), participated in the experiment. Their ages were $29,25,33$, and 30 years, respectively. Subject R.U. is the first author of this article.

Procedures. All RT sessions were conducted with the subject seated in a sound-attenuated chamber. The beginning of an experimental trial was signaled by the lighting of a lamp in front of the subject. The subject started the trial by pressing a button with his foot. After a random foreperiod, a loud (100 dB SPL) or a soft ( $60 \mathrm{~dB}$ SPL) $1000-\mathrm{Hz}$ sinusoidal tone was presented binaurally over $\mathrm{KOSS}+\mathrm{PRO} / 4 \mathrm{AA}$ headphones. The subject responded as fast as possible upon detection of a tone. The subject's response terminated the tone immediately.

The purpose of the random foreperiod was to avoid premature or anticipatory responses. The random foreperiod was never less than $1 \mathrm{sec}$. In every trial, an exponentially distributed random variable was added to this base duration. The mean of this random variable was $1 \mathrm{sec}$. If a response occurred prior to the tone onset, a 
false alarm was indicated and punished by the flashing of the lamp for $20 \mathrm{sec}$ to discourage anticipatory responses.

Two Morse keys in front of the subject served as response buttons for each hand separately. The subject was instructed to press the response buttons with the index fingers as fast as possible upon detecting the tone. A minimum force of approximately $50 \mathrm{~g}$ on the key was needed to stop the time counter. RT was recorded from tone onset to keypress for each hand separately. After the slowest response was recorded, there was a $1.5-\mathrm{sec}$ pause before the next trial was signaled.

A single session consisted of 100 soft and 100 strong tone presentations in random order. After 100 trials, there was a 4-min rest. Each subject received 2 training and 10 experimental sessions.

\section{Results and Discussion}

The RT statistics reported below are based on the whole RT distribution of all 10 sessions for each subject and each condition. Averaging the statistics of all 10 sessions yielded nearly the same values. RTs outside the range (70$450 \mathrm{msec}$ ) were considered as outliers and were excluded from data analysis. Outliers may have a profound effect upon the estimated parameters. This is true for early responses released by anticipation and for the very late responses which subjects often ascribe to inattention.

The results for each subject and condition are summarized in Table 1. Row 1 gives the total number of analyzed responses, after excluding outliers, for estimating the parameters listed directly below. Only very few outliers had to be excluded from the total of 1,000 responses per intensity condition and subject.

Simple RT. A profound and consistent intensity effect with several features resulted for simple RTs of the left and right hand, as shown in parts $\mathrm{b}$ and $\mathrm{c}$ of Table 1 . (1) Significantly shorter RTs resulted in the loud condi- tion. The average difference between the two conditions is about 50 msec. (2) The standard deviations are smaller in the loud condition. On average, there is a 14-msec difference. (3) RT distributions are more skewed to the right in the loud condition. (4) For Subjects G.U., K.M., and T.H., the RT distributions are more peaked in the loud condition, as indicated by kurtosis. Of all subjects, T.H.'s RT distribution is the most affected by the loud condition. In general, the RTs for the right hand are faster than those for the left. However, this difference is very small-an average of $3.6 \mathrm{msec}$. Absolute mean RT difference is smaller in Condition Loud than in Condition Soft. RT distributions of both hands have nearly identical standard deviations and skewnesses. Only kurtosis shows a tendency to be smaller for the right-hand RT.

RT difference. A strong intensity effect is also observable for the RT difference distribution, as shown in part a of Table 1 and in Figure 2: (1) As expected, standard deviations decreased consistently with intensity for all subjects and reached statistical significance utilizing an $F$ test. The corresponding F values for G.U., K.M., T.H., and R.U. are $1.19(\mathrm{p}<.05), 2.29(\mathrm{p}<.001), 8.68$ $(\mathrm{p}<.001)$ and $1.61(\mathrm{p}<.05)$, respectively. The mean standard deviation of RT difference is $7.5 \mathrm{msec}$ for Condition Loud and $12.4 \mathrm{msec}$ for Condition Soft. Although this effect is (necessarily) small in terms of milliseconds, it is large in relative terms: standard deviations in the loud condition are reduced by $40 \%$ relative to the soft condition.

(2) Although intensity affected skewness, no general tendency is observable. With intensity, skewness increased for G.U. and R.U. and decreased for K.M. and T.M. The distributions are all leptokurtic and become

Table 1

Analysis of RTs for Experiment 1

\begin{tabular}{|c|c|c|c|c|}
\hline \multirow[b]{2}{*}{ Statistics } & \multicolumn{4}{|c|}{ Subjects } \\
\hline & G.U. & K.M. & T.H. & R.U. \\
\hline Total Number of Responses & $985 / 994$ & $994 / 993$ & $982 / 989$ & $992 / 994$ \\
\hline \multicolumn{5}{|c|}{ (a) Summary Statistics for RT Difference } \\
\hline $\begin{array}{l}\text { 1. Mean Difference Time (msec) } \\
\text { 2. Standard Deviation }(\mathrm{msec}) \\
\text { 3. Skewness } \\
\text { 4. Kurtosis } \\
\text { 5. Standard Deviation of the Motor Delay } \\
\text { 6. } \operatorname{var}(\mathrm{S}) / \mathrm{var}(\mathrm{M})\end{array}$ & $\begin{array}{c}5 / 3 \\
12 / 10 \\
-.1 / 1.1 \\
5 / 16 \\
8 / 7 \\
14 / 10\end{array}$ & $\begin{array}{c}8 / 6 \\
11 / 7 \\
3.2 /-4.4 \\
42 / 55 \\
8 / 5 \\
24 / 24\end{array}$ & $\begin{array}{c}-1 / 2 \\
17 / 6 \\
-.8 /-2.9 \\
30 / 42 \\
12 / 4 \\
19 / 24\end{array}$ & $\begin{array}{c}5 / 1 \\
9 / 7 \\
2.4 / 1.1 \\
29 / 29 \\
7 / 5 \\
32 / 32\end{array}$ \\
\hline
\end{tabular}

(b) Summary Statistics for Simple RT of the Left Hand

1. Mean RT (msec)

3. Skewness

4. Kurtosis

1. Mean RT (msec)

2. Standard Deviation (msec)

3. Skewness

4. Kurtosis
2. Standard Deviation (msec)

$\begin{array}{cc}182 / 153 & 186 / 147 \\ 32 / 25 & 38 / 24 \\ 1.5 / 4.5 & 1.2 / 2.3 \\ 1180 / 1787 & 703 / 1545 \\ \text { Statistics for Simple RT of the Right Hand } \\ 177 / 150 & 178 / 141 \\ 33 / 25 & 40 / 26 \\ 1.7 / 4.6 & 1.3 / 2.4 \\ 972 / 1662 & 512 / 1046\end{array}$

$197 / 116$

$53 / 20$

$.7 / 4.1$

278/1395

(c) Summary Statistics for Simple RT of the Right Hand

$1.3 / 2.4$

\begin{tabular}{cc}
$198 / 114$ & $194 / 146$ \\
$54 / 23$ & $35 / 31$ \\
$.6 / 5.1$ & $.2 / 2.6$ \\
$265 / 1045$ & $1135 / 695$ \\
\hline
\end{tabular}

$199 / 147$

$35 / 32$

$.3 / 2.9$

$1199 / 658$
Note-The number before (after) the slash indicates the data for the soft (loud) condition. Mean, standard deviation, and kurtosis are rounded to the nearest whole number, and skewness is rounded to the nearest decimal. 


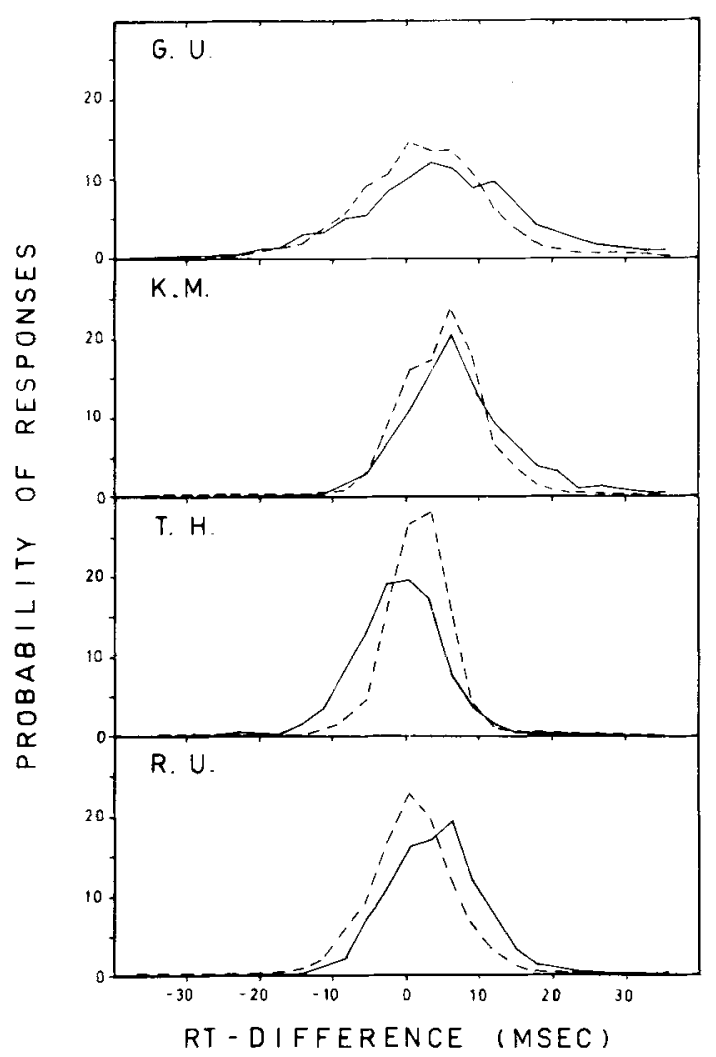

Figure 2. Distributions of RT difference between left and right hands for Subjects T.H., G.U., K.M., and R.U. Conditions Soft (solid lines) and Loud (dashed lines). Each distribution is based on about 980 RT measures, and the bin size is $3 \mathrm{msec}$.

more peaked with increasing intensity, as shown by kurtosis.

The fifth row of part a in Table 1 shows the estimated standard deviations of the motor delay according to Equation 3. The averaged standard deviations are 8.8 and $5.3 \mathrm{msec}$ for Conditions Soft and Loud, respectively. These estimates are slightly greater than the one found in finger-tapping experiments (Vorberg \& Hambuch, 1977; Wing \& Kristofferson, 1973). This slight disagreement is not suprising, inasmuch as movements in simple RT are ballistic and movements in finger-tapping experiments probably need feedback from the muscle spindels and the tendon organs, which improves the accuracy of the movements. As a consequence, the variance of the motor delay would be smaller in finger-tapping experiments, and therefore they offer a reasonable lower bound for the estimates in our study.

An upper bound for the estimated motor delay variance is provided by a consideration of the Kohfeld (1982) and Kohfeld et al. (1981) studies. These authors decomposed the overall simple auditory RT into a sensory and a residual distribution. The residual distribution corresponded to the RT distribution, which was obtained under the strongest intensity level employed. They suggested that the variance of the RT distribution obtained at strong in- tensities had probably reached minimum, or an "irreducible" level. The standard deviations of this residual component ranged from 9 to $13 \mathrm{msec}$. These values offer a reasonable upper bound for the standard deviation of the motor delay for Condition Loud in our study. The estimated standard deviations according to Equation 3 are below this upper bound, as claimed.

Unfortunately, a direct comparison of our results with those of Botwinick and Thompson (1966) is not possible. They published only the variance ratio of premotor time (from stimulus onset to EMG onset) and motor time, and not the variance of the motor time (from EMG onset until keypressing). We will utilize their ratio, which appears to be in the range 5 to 10 , for assessing whether or not the latencies $S$ and $M$ in our study are correlated.

A major difference between the Botwinick and Thompson study and ours is the location of where Stage $S$ ends. The component $S$ in our study certainly does not extend down to the muscle as did the premotor component measured by Botwinick and Thompson. Therefore, the variance ratio $\operatorname{var}(\mathrm{S}) / \operatorname{var}(\mathrm{M})$ in our study should be smaller than Botwinick and Thompson's. This aspect should be kept in mind when comparing the variance ratios for our study with those of Botwinick and Thompson.

In Appendix A, we derived the variance ratio $\operatorname{var}(\mathbf{S}) /$ $\operatorname{var}(\mathrm{M})$ for our paradigm:

$$
\begin{aligned}
& \operatorname{var}(S) / v a r(M) \\
&= {\left[\operatorname{var}\left(R_{L}\right)+\operatorname{var}\left(R T_{R}\right)-\operatorname{var}\left(R_{T} T_{L}-R_{R}\right)\right.} \\
&\left.-2 \operatorname{cov}\left(M_{L}, M_{R}\right)-4 \operatorname{cov}(S, M)\right] \\
& /\left[\operatorname{var}\left(R_{T} T_{L}-R_{R}\right)+2 \operatorname{cov}\left(M_{L}, M_{R}\right)\right],
\end{aligned}
$$

where $\operatorname{cov}(S, M)$ is defined as the average for $\operatorname{cov}\left(S, M_{L}\right)$ and $\operatorname{cov}\left(S, M_{R}\right)$. It is clear that the true variance ratio for our study cannot be computed unless we know the concrete numeric values of $\operatorname{cov}(\mathbf{S}, \mathrm{M})$ and $\operatorname{cov}\left(\mathrm{M}_{\mathbf{L}}, \mathrm{M}_{\mathrm{R}}\right)$. However, a useful baseline is established if the two expressions $\operatorname{cov}(\mathrm{S}, \mathrm{M})$ and $\operatorname{cov}\left(\mathrm{M}_{\mathrm{L}}, \mathrm{M}_{\mathrm{R}}\right)$ are set to zero, that is, if one assumes that the processing times in the different components do not correlate. Under these conditions, Equation 4 simplifies to:

$$
\begin{aligned}
& \operatorname{var}(\mathbf{S}) / \operatorname{var}(\mathbf{M}) \\
& \quad=\left[\operatorname{var}\left(\mathrm{RT}_{\mathbf{L}}\right)+\operatorname{var}\left(\mathrm{RT}_{\mathbf{R}}\right)\right] / \operatorname{var}\left(\mathrm{RT}_{\mathbf{L}}-\mathbf{R T}_{\mathbf{R}}\right)-1 .
\end{aligned}
$$

It follows from Equation 4 that Equation 5 overestimates (underestimates) the true variance ratio if $\operatorname{cov}(\mathrm{S}, \mathrm{M})$ and/or $\operatorname{cov}\left(M_{L}, M_{R}\right)$ is positive (negative).

The estimated variance ratios according to Equation 5 are shown in part a of Table 1 . For each subject, the variance ratio is much greater than 1 , ranging from 10 to 32. These variance ratios are greater than those reported by Botwinick and Thompson. Since the true variance ratios in our study should, in any case, be smaller than those 
reported by Botwinick and Thompson, we know that Equation 5 overestimates. We have pointed out that Equation 5 overestimates the true variance ratio if $\operatorname{cov}(\mathrm{S}, \mathrm{M})$ and/or $\operatorname{cov}\left(M_{L}, M_{R}\right)$ are positive. Therefore, the greater variance ratios in our studies might be due to a positive correlation of the components $S$ and $M$ and/or $M_{L}$ and $\mathbf{M}_{\mathbf{R}}$. Since the estimates of $\operatorname{var}(\mathbf{M})$ are greater than those obtained in finger-tapping experiments, we can rule out a profound positive correlation between $M_{L}$ and $M_{R}$ according to Equation 2. However, if we assume a positive correlation between $S$ and $M$, the greater variance ratios in our study can be explained. Thus, the comparison of the variance ratios in our studies with those of Botwinick and Thompson leads to the conclusion that the motor delay and the sensory stage are probably positively correlated. This conclusion would also support the conjecture that when $S$ is speeded up with increasing intensity, $\mathbf{M}$ is speeded up, too.

The intensity effect on the RT difference distribution is also accompanied by movements that are much more vigorous in the loud condition than in soft condition. Subjects stated that, with soft tones, they had the feeling that their fingers were pressing the response key more slowly than they intended. In the loud trials, on the other hand, they felt they were pressing more rapidly and reflexively. The vigorous movements observed by a harder click in the loud condition might be affected by the recruitment of a greater number of motor units. Wood (1977) observed a close relationship between EMG energy as an indicator of the number of motor units involved, on the one hand, and movement acceleration and movement velocity in simple RT, on the other. This additional observation also supports the claim that the motor process is speeded up with intensity.

Correlation analysis of RTs. Additional insights into the behavior of the components $\mathbf{S}$ and $\mathrm{M}$ can be gained if the correlation between $\mathrm{RT}_{\mathrm{L}}$ and $\mathrm{RT}_{\mathrm{R}}$ and the correlation between simple RT and RT difference are investigated. The relation $R T=S+M$ can be used to derive testable baselines for the case that $S$ and $M$ are independent stages and, consequently, that $M$ is not influenced by stimulus intensity. As we will show in this section, these predictions are not confirmed by the data, which provides additional evidence that the behavior or the motor stage changes with changing stimulus intensity.

The correlation $\operatorname{corr}\left(R_{L}, R_{T}\right)$ between $R_{T}$ and $R T_{R}$ can be expressed in terms of the components $S, M_{L}$, and $M_{R}$ (cf. Appendix A):

$$
\begin{aligned}
\operatorname{corr} & \left(R_{T_{L},} \mathbf{R T}_{\mathbf{R}}\right) \\
= & {\left[\operatorname{var}(\mathbf{S})+\operatorname{cov}\left(\mathbf{S}, \mathbf{M}_{\mathbf{R}}\right)+\operatorname{cov}\left(\mathbf{S}, \mathbf{M}_{\mathbf{L}}\right)+\operatorname{cov}\left(\mathbf{M}_{\mathbf{R}}, \mathbf{M}_{\mathbf{L}}\right)\right] } \\
& /\left[\left\{\left[\operatorname{var}(\mathbf{S})+\operatorname{var}\left(\mathbf{M}_{\mathbf{L}}\right)+2 \cdot \operatorname{cov}\left(\mathbf{S}, \mathbf{M}_{\mathbf{L}}\right)\right]\right.\right. \\
& \left.\left.\cdot\left[\operatorname{var}(\mathbf{S})+\operatorname{var}\left(\mathbf{M}_{\mathbf{R}}\right)+2 \cdot \operatorname{cov}\left(\mathbf{S}, \mathbf{M}_{\mathbf{R}}\right)\right]\right\}^{1 / 2}\right]
\end{aligned}
$$

where $\operatorname{cov}\left(S, M_{L}\right), \operatorname{cov}\left(S, M_{R}\right)$, and $\operatorname{cov}\left(M_{L}, M_{R}\right)$ are the covariances between the components $S, M_{L}$, and $M_{R}$.
If one assumes that $S$ and $M$ are independent stages, the covariance between $S$ and $M$ should be zero. According to this assumption, Equation 6 can be simplified and rearranged to:

$$
\begin{aligned}
& \operatorname{corr}^{2}\left(R_{T}, R_{R}\right) \\
&=1-\left\{\operatorname{var}(S)\left[\operatorname{var}\left(M_{R}\right)+\operatorname{var}\left(M_{L}\right)-2 \operatorname{cov}\left(M_{R}, M_{L}\right)\right]\right. \\
&\left.+\operatorname{var}\left(M_{L}\right) \operatorname{var}\left(M_{R}\right)\left[1-\operatorname{corr}\left(M_{L}, M_{R}\right)^{2}\right]\right\} \\
& /\left\{\operatorname{var}(S)^{2}+\operatorname{var}(S)\left[\operatorname{var}\left(M_{R}\right)+\operatorname{var}\left(M_{L}\right)\right]\right. \\
&\left.+\operatorname{var}\left(M_{L}\right) \operatorname{var}\left(M_{R}\right)\right\} .
\end{aligned}
$$

The fraction in Equation 7 is decreasing with increasing $\operatorname{var}(\mathbf{S})$. Consequently, if $\operatorname{var}(S)$ increases, so does the correlation between $\mathrm{RT}_{\mathrm{L}}$ and $\mathrm{RT}_{\mathrm{R}}$. We can test this prediction by comparing the correlations between $\mathrm{RT}_{\mathrm{L}}$ and $\mathrm{RT}_{\mathrm{R}}$ in Conditions Soft and Loud. The prediction is that the correlations will be greater in Condition Soft than in Condition Loud. This follows from the fact that the variances of simple RT did decrease with increasing intensity [see (b) and (c) in Table 1], which must be attributed to a decreasing variance of $S$ if it is assumed that only the variance of $S$ and not of $M$ is influenced by intensity. Therefore, if $\mathbf{M}$ is not influenced by stimulus intensity, the correlation between $\mathrm{RT}_{\mathrm{L}}$ and $\mathrm{RT}_{\mathrm{R}}$ should decrease with increasing stimulus intensity.

Table 2 (first column) gives the correlations between $\mathrm{RT}_{L}$ and $\mathrm{RT}_{\mathrm{R}}$ for each subject and stimulus condition. The correlations are very high, as one might expect on the basis of Equation 6, for a large variance of component $S$ relative to the small variances of components $M_{\mathbf{L}}$ and $M_{R}$. The above prediction was confirmed only for Subject G.U. For this subject, the correlation decreased with increasing intensity $(\mathrm{z}=2.9, \mathrm{p}<.001)$. There was no change with intensity for Subjects K.M. and R.U. For Subject T.H., the correlation even increased with intensity $(\mathrm{z}=5.8, \mathrm{p}<.001)$. The overall pattern shows no change in the correlation between $R_{L}$ and $R T_{R}$ with intensity. This result contradicts the assumption that $S$ and $\mathbf{M}$ are independent stages.

However, if one assumes that the variance of the motor delay also decreases with increasing stimulus intensity, then it can be demonstrated that the correlation of both RTs remains nearly unchanged with increasing stimulus intensity. To give a concrete example, let us assume the following parameters for Condition Loud: $\operatorname{var}(S)=$ $600 \mathrm{msec}^{2}, \operatorname{var}\left(\mathrm{M}_{\mathrm{L}}\right)=\operatorname{var}\left(\mathrm{M}_{\mathrm{R}}\right)=45 \mathrm{msec}^{2}, \operatorname{corr}\left(\mathrm{S}, \mathrm{M}_{\mathrm{R}}\right)$ $=\operatorname{corr}\left(\mathrm{S}, \mathrm{M}_{\mathrm{L}}\right)=.6$, and $\operatorname{corr}\left(\mathrm{M}_{\mathrm{L}}, \mathrm{M}_{\mathrm{R}}\right)=.10$. Using Equation 6, one obtains corr $\left(R T_{L}, R_{R}\right)=.95$. Now, for Condition Soft, let us assume that the variances of $\mathrm{S}$ and the motor delays increased: $\operatorname{var}(\mathbf{S})=1,200 \mathrm{msec}^{2}$ and $\operatorname{var}\left(\mathrm{M}_{\mathrm{L}}\right)=\operatorname{var}\left(\mathrm{M}_{\mathrm{R}}\right)=100 \mathrm{msec}^{2}$. Using Equation 6 again, the computation is corr $\left(\mathrm{RT}_{\mathrm{L}}, \mathrm{RT}_{\mathbf{R}}\right)=.95$, which is the same value as that obtained in Condition Loud.

Table 2 (columns 2 and 3 ) also shows the correlations 
Table 2

Correlation Analysis of RTs for Experiment 1

\begin{tabular}{lccc}
\hline \multicolumn{1}{c}{ Subject } & $\operatorname{corr}\left(\mathrm{RT}_{\mathrm{L}}, \mathrm{RT}_{\mathrm{R}}\right)$ & $\operatorname{corr}\left(\mathrm{RT}_{\mathrm{L}}, \mathrm{RT}_{\mathrm{L}}-\mathrm{RT}_{\mathrm{R}}\right)$ & $\operatorname{corr}_{\left(\mathrm{RT}_{\mathrm{R}}, \mathrm{RT}_{\mathrm{R}}-\mathrm{RT}_{\mathrm{L}}\right)}$ \\
\hline G.U. & $.93 / .91$ & $.11 / .20$ & $.25 / .21$ \\
K.M. & $.96 / .96$ & $-.03 /-.11$ & $.30 / .38$ \\
T.H. & $.95 / .97$ & $.10 /-.16$ & $.21 / .41$ \\
R.U. & $.97 / .97$ & $.17 / .24$ & $.09 /-.01$ \\
Mean & $.95 / .95$ & $.09 / .04$ & $.22 / .25$ \\
Mean Percentage of & & & \\
Common Variance & $91 \% / 91 \%$ & $1 \% / 3 \%$ & $5 \% / 9 \%$ \\
\hline
\end{tabular}

Note-The number before (after) the slash indicates the data for the soft (loud) condition. The underlined correlations do not differ significantly from zero $(\alpha=.05$, two-tailed).

of simple RT with RT difference for each subject and the two intensity conditions. The second column shows the correlation corr $\left(\mathrm{RT}_{\mathrm{L}}, \mathrm{RT}_{\mathrm{L}}-\mathrm{RT}_{\mathrm{R}}\right)$ between the simple $\mathrm{RT}$ of the left hand and RT difference. The correlation $\operatorname{corr}\left(R T_{R}, R T_{R}-R T_{L}\right)$ between simple $R T$ of the right hand and RT difference is shown in the third column. For the latter correlation, the sign of RT difference is changed for reasons of comparison.

The percentage of common variance between simple RT and RT difference is small, as can be seen by the average coefficient of determination, which is summarized at the bottom row of Table 2 . This coefficient ranges from $1 \%$ to $9 \%$. RT difference depends more on $\mathrm{RT}_{\mathrm{R}}$ than on $\mathrm{RT}_{\mathrm{L}}$. The corresponding average coefficients are $2 \%$ and $6 \%$, respectively. The coefficient of determination is also affected by stimulus intensity (soft, $3 \%$; loud, $6 \%$ ).

The correlation coefficients of simple RT and RT difference are surprisingly consistent within subjects: For Subjects G.U., K.M., and K.H., the correlation between $R_{T_{R}}$ and RT difference is higher than the one between $\mathrm{RT}_{\mathbf{L}}$ and RT difference. For Subject R.U., this is reversed. However, within subjects, this pattern does not change with intensity. Nearly all correlations differ significantly from zero. The negative correlations obtained for K.M. and T.H. are a surprising feature and are difficult to explain.

For a discussion of these results, it will be useful again to express the corresponding correlations in terms of $S$ and $M$ (cf. Appendix A):

$$
\begin{aligned}
\operatorname{corr}( & \left.R T_{L}, R_{T}-R T_{R}\right) \\
= & {\left[\operatorname{cov}\left(S, M_{L}\right)-\operatorname{cov}\left(S, M_{R}\right)+\operatorname{var}\left(M_{L}\right)-\operatorname{cov}\left(M_{L}, M_{R}\right)\right] } \\
& /\left[S D\left(R T_{L}\right) S D\left(R T_{L}-R_{R}\right)\right] \\
\operatorname{corr}\left(R T_{R}, R T_{R}-R T_{L}\right) & (8 a) \\
= & {\left[\operatorname{cov}\left(S, M_{R}\right)-\operatorname{cov}\left(S, M_{L}\right)+\operatorname{var}\left(M_{R}\right)-\operatorname{cov}\left(M_{L}, M_{R}\right)\right] } \\
& /\left[S D\left(R T_{L}\right) S D\left(R T_{L}-R T_{R}\right)\right]
\end{aligned}
$$

The denominators of Equations $8 \mathrm{a}$ and $8 \mathrm{~b}$ differ with regard to the standard deviations of $R T_{L}$ and $R T_{R}$, respec- tively. Since the obtained standard deviations of $\mathrm{RT}_{\mathrm{L}}$ and $\mathrm{RT}_{\mathbf{R}}$ are virtually equal, one can focus on the numerators for comparing the two correlations.

Let us first discuss the prediction of Equations 8a and $8 \mathrm{~b}$ for the case in which $S$ and $M$ are independent stages. Under the independent-stage assumption, $S$ and $M$ should not correlate. Accordingly, the covariances $\operatorname{cov}\left(S, M_{L}\right)$ and $\operatorname{cov}\left(\mathbf{S}, \mathrm{M}_{\mathbf{R}}\right)$ are set to zero. Equations $8 \mathrm{a}$ and $8 \mathrm{~b}$ would therefore differ only in respect of $\operatorname{var}\left(\mathbf{M}_{\mathbf{L}}\right)$ and $\operatorname{var}\left(\mathbf{M}_{\mathbf{R}}\right)$, respectively. Since it was found that on average the correlation between $\mathrm{RT}_{\mathrm{R}}$ and $\mathrm{RT}$ difference is greater than that between $\mathrm{RT}_{\mathrm{L}}$ and $\mathrm{RT}$ difference, one is forced, under the independent-stage assumption, to conclude that $\operatorname{var}\left(\mathrm{M}_{\mathrm{R}}\right)$ is greater than $\operatorname{var}\left(\mathbf{M}_{\mathbf{L}}\right)$. However, this conclusion is not very promising, since the right hand of each subject was the more trained one, suggesting lesser variance of the right motor delay relative to the left one. It is also difficult to predict the negative and very high obtained correlations when assuming that $S$ and $M$ are independent stages.

Let us now assume that $S$ and $M$ are dependent stages. Consequently, there should be a positive correlation between stages $S$ and $M$. In addition, it is reasonable to assume that the correlation between $S$ and $M$ of the more trained, right hand is greater than the one of the less trained, left hand. With these assumptions, the whole pattern of results can be predicted fairly well. A numerical example using Equation 8 might be useful to illustrate the predictions at this point:

Let us assume the following correlations $\operatorname{corr}\left(\mathrm{RT}_{\mathrm{S}}, \mathrm{M}_{\mathrm{R}}\right)$ $=.8$ and $\operatorname{corr}\left(\mathrm{RT}_{\mathrm{S}}, \mathrm{M}_{\mathrm{L}}\right)=.4$ between $\mathrm{M}$ and $\mathrm{S}$ for the right and left hands, respectively. Both correlations are assumed to be the same for both intensity conditions (although a small increase is probable in view of the fact that the common variance of simple RT and RT difference increased with intensity). In addition, we admit a small correlation of 1 between $M_{L}$ and $M_{R}$, which might be linked to variation in alertness over trials. For Condition Soft, the variances of $S, M_{R}$, and $M_{L}$ are 600,25 , and $30 \mathrm{msec}^{2}$, respectively. By using the corresponding equations, one obtains, for these parameters: $\operatorname{corr}\left(\mathrm{RT}_{\mathrm{L}}, \mathrm{RT}_{\mathrm{L}}-\mathrm{RT}_{\mathrm{R}}\right)=-.09, \operatorname{corr}\left(\mathrm{RT}_{\mathrm{R}}, \mathrm{RT}_{\mathrm{R}}-\mathrm{RT}_{\mathrm{L}}\right)=$ .33, $\mathrm{SD}\left(\mathrm{RT}_{\mathrm{L}}\right)=27.2 \mathrm{msec}, \mathrm{SD}\left(\mathrm{RT}_{\mathrm{R}}\right)=28.6 \mathrm{msec}$, $\mathrm{SD}(\mathrm{D})=7 \mathrm{msec}$, and $\operatorname{corr}\left(\mathrm{RT}_{\mathrm{L}}, \mathrm{RT}_{\mathrm{R}}\right)=.97$. It can be seen that the above assumptions of dependent stages $S$ and $M$ can predict the obtained results in Table 2 and even 
the obtained negative correlations. It is also pedicted that the standard deviation of the right hand is greater than that of the left hand. This is also confirmed by the data in Table 1. Averaging the standard devations over the subjects, one obtains 25.5 and $26.3 \mathrm{msec}$ for the left and right hands, respectively.

For Condition Soft, it is again assumed that the variances of $S, M_{L}$, and $M_{R}$ increase- $v a r(S)=1,200 \mathrm{msec}^{2}$, $\operatorname{var}\left(M_{L}\right)=70 \mathrm{msec}^{2}$ and $\operatorname{var}\left(M_{R}\right)=60 \mathrm{msec}^{2}$-while the intercorrelations between them remain unchanged. For these values, the following predictions result: $\operatorname{corr}\left(\mathrm{RT}_{\mathrm{L}}, \mathrm{RT}_{\mathrm{L}}-\mathrm{RT}_{\mathrm{R}}\right)=-.08, \operatorname{corr}\left(\mathrm{RT}_{\mathrm{R}}, \mathrm{RT}_{\mathrm{R}}-\mathrm{RT}_{\mathrm{L}}\right)=$ $.34, \mathrm{SD}\left(\mathrm{RT}_{\mathrm{L}}\right)=38.8 \mathrm{msec}, \mathrm{SD}\left(\mathrm{RT}_{\mathrm{R}}\right)=41.0 \mathrm{msec}$, $\mathrm{SD}(\mathrm{D})=10 \mathrm{msec}$, and $\operatorname{corr}\left(\mathrm{RT}_{\mathrm{L}}, \mathrm{RT}_{\mathrm{R}}\right)=.97$. The average pattern of the correlation between simple RT and RT difference is predictable inasmuch as there is also a slight increase in the obtained correlations with intensity. Standard deviations of simple RT were predicted to decrease with intensity. This is clearly confirmed. According to this numerical example, the standard deviation of the right hand in Condition Loud is also slightly greater than that of the left hand. A look at Table 1 also confirms this prediction (39.5 and $40.5 \mathrm{msec}$ for left and right hands, respectively).

A summarization of the results and the discussions leads to the following picture: RT difference distribution is affected by intensity, as can be seen in the first four moments of the RT difference distribution. The main finding is that the variance of RT difference decreased with increasing intensity. This finding indirectly provides evidence that mean motor delay decreased with stimulus intensity. A comparison of Botwinick and Thompson's results with ours and the correlation analysis leads to the conclusion that the motor delay and the component $S$ are positively correlated, that is, there is a dependence also between the two components within a constant intensity level. The comparison of the correlation between simple RT and RT difference for the left and right hands provides evidence that the correlation between $M_{R}$ and $S$ is greater than that between $M_{L}$ and $S$. In short, then, the motor delay is not an independent stage, and the behavior of this stage changes with stimulus intensity.

\section{EXPERIMENT 2}

Do the results observed in Experiment 1 depend on specific modality effects in audition and would they therefore not be observable with another sense modality, for example, visual stimuluation? This possibility should be dealt with, because there are well-known modality differences-for example, those between visual and auditory simple RT, to name but two.

First, previous investigations of simple RT have indicated that auditory RT is shorter than visual RT (Elliott, 1968; Goldstone, 1968; Todd, 1912). This may be due to a closer link between the sensory and motor system in audition. It might be, then, that the motor system is only speeded up with sound intensity. However, the results of Kohfeld (1971) question this common view. In his experiments, he composed simple auditory and simple visual RT on the same scale by presenting psychophysically equivalent response signals. When the white-light levels were above the photopic threshold, the obtained simple visual RTs were similar to those obtained for sound levels in the same range. That is, if the energies of the visual and auditory stimuli are equated, the RT difference of visual and auditory disappears. In such a case, the idea of a closer link between the auditory system and the motor system must be questioned and the same effects upon RT difference found in the first experiment should result in simple visual RT.

Another modality difference observed in simple RT is alertness. Posner (1975) has defined alertness as a state in which an organism's central decision mechanism is activated and made ready to respond to incoming information. The consequences of this state include a decrease in simple RT. It has been proposed that visual and auditory stimuli differ in their alerting characteristics: Visual stimuli seem to produce little or no alteration as a function of stimulus intensity. It may be, therefore, that auditory intensity effects upon the motor system are caused indirectly by alertness. As a consequence, the results observed in Experiment 1 should disappear with visual stimulation, if they depend on alertness.

A second consideration also motivated our attempt to replicate the results of Experiment 1 in another sense modality. If the final pathways of $M_{L}$ and $M_{R}$, measured indirectly by RT difference, are the same for every sense modality, we should observe about the same RT difference distribution using a different kind of stimulation from that used in Experiment 1.

\section{Method}

The procedure was identical to that of Experiment 1 with the exception that a strong and a weak visual stimuli was used instead of loud and soft tones. A yellow light-emitting diode (OPCOA, LSM-28L-A1) was used as the visual stimulus. The diode was installed on a black light-absorbing panel $80 \mathrm{~cm}$ in front of the subject and subtended a visual angle of $.43^{\circ}$. It was supplied with $1.5 \mathrm{~V}$ and currents of 5 and $40 \mathrm{~mA}$ for weak and strong stimulation, respectively.

Three right-handed subjects (M.P., T.H., and R.U.) participated. T.H. and R.U. had participated in Experiment 1 too. In each intensity condition, the subjects completed 300 trials after 100 practice trials.

\section{Results and Discussion}

RTs outside the range of 70-450 msec were excluded from data analysis, as in Experiment 1. Table 3 displays the results of Experiment 2. A maximum of only 7 RTs had to be excluded from the total of 300 responses per condition and subject.

Simple RT. A clear stimulus effect for the left and right hands on mean RT resulted for each subject, as can be seen in parts $b$ and $c$ of Table 3. The RTs are on average $46 \mathrm{msec}$ faster for strong visual stimulation than for the 
Table 3

Analysis of RTs for Experiment 2

\begin{tabular}{|c|c|c|c|}
\hline \multirow[b]{2}{*}{ Statistics } & \multicolumn{3}{|c|}{ Subjects } \\
\hline & M.P. & T.H. & R.U. \\
\hline Total Number of Responses & $294 / 296$ & $295 / 293$ & $296 / 299$ \\
\hline \multicolumn{4}{|c|}{ (a) Summary Statistics for RT Difference } \\
\hline 1. Mean Difference Time (msec) & $3 / 6$ & $0 / 1$ & $-7 /-5$ \\
\hline 2. Standard Deviation (msec) & $17 / 14$ & $5 / 4.6$ & $11 / 7$ \\
\hline 3. Skewness & $-4.6 / 4.4$ & $-.2 / .2$ & $-3.3 / .1$ \\
\hline 4. Kurtosis & $25 / 42$ & $3 / 4$ & $38 / 5$ \\
\hline 5. Standard Deviation of the Motor Delay & $12 / 10$ & $4 / 3$ & $8 / 5$ \\
\hline 6. $\operatorname{var}(\mathrm{S}) / \operatorname{var}(\mathrm{M})$ & $24 / 28$ & $71 / 99$ & $32 / 57$ \\
\hline \multicolumn{4}{|c|}{ (b) Summary Statistics for Simple RT of the Left Hand } \\
\hline 1. Mean RT (msec) & $305 / 253$ & $217 / 185$ & $271 / 221$ \\
\hline 2. Standard Deviation (msec) & $58 / 53$ & $30 / 33$ & $43 / 37$ \\
\hline \multicolumn{4}{|c|}{ (c) Summary Statistics for Simple RT of the Right Hand } \\
\hline 1. Mean RT (msec) & $302 / 247$ & $218 / 184$ & $279 / 225$ \\
\hline 2. Standard Deviation (msec) & $59 / 54$ & $30 / 32$ & $47 / 39$ \\
\hline
\end{tabular}

Note-The number before (after) the slash indicates the data for the soft (loud) condition. Mean, standard deviation, and kurtosis are rounded to the nearest whole number, and skewness is rounded to the nearest decimal.

soft stimulus. This difference is about the same as in Experiment 1, although the RTs in Experiment 2 are longer.

Stimulus intensity did not have the same effect upon RT standard deviations as it did in Experiment 1. Significant $F$ ratios comparing the intensity effect for each hand separately resulted only for Subject R.U. $(F=1.45$, $\mathrm{p}<.05$, for $\mathrm{RT}_{\mathrm{R}}$ and $\mathrm{F}=1.35, \mathrm{p}<.05$, for $\left.\mathrm{RT}_{\mathrm{L}}\right)$. The smallest intensity effect is observable for T.H.

RT difference. The statistics of RT difference are summarized in part a of Table 3. These statistics are in general similar to those of Experiment 1. Standard deviations decreased again with intensity for all subjects and reached statistical significance for M.P. $(F=1.5, p<.05)$ and for R.U. ( $F=2.5, p<.01)$.

The estimated ratios of $\operatorname{var}(\mathbf{S}) / \operatorname{var}(\mathbf{M})$, according to Equation 5, are larger in Experiment 2, and range from 24 to 99 . This disagreement suggests greater variability for visual detection times. The proposition is strengthened as follows: First, mean detection time and variance are probably positively correlated. Second, longer detection times for visual than for auditory stimuli can be inferred from the results of temporal order judgments. To perceive a tone onset and a light onset as simultaneous, the light must precede the onset of the tone (Exner, 1875; Fröh- lich, 1929). Both arguments, taken together, support the notion that $S$ has greater variability in Experiment 2 .

The RT difference distributions for T.H. and R.U. between Experiment 1 and Experiment 2 show some different features. For T.H., smaller standard deviations resulted in both conditions of Experiment 2. The same is true for kurtosis. For R.U., the mean RT difference was strongly influenced by sensory modality. Mean RT difference is positive in Experiment 1, whereas it is negative in Experiment 2. However, nearly the same standard deviations resulted for R.U. in both experiments.

Correlation analysis. The correlations between simple RTs and between simple RTs and RT difference are shown in Table 4 in the same way as in Table 2 for Experiment 1 . The correlations of simple RTs are slightly greater than those obtained in Experiment 1. This is not surprising, since the variance of $\mathrm{S}$ is probably greater in Experiment 2 than in Experiment 1 because, as shown previously (cf. Equation 7), as var(S) increases with no or only a little increase of the motor delay, the correlation of the simple RTs increases, too. Again, the correlations did not decrease with intensity as would be the case if $\operatorname{var}(\mathbf{M})$ did not change with intensity.

The pattern of the correlation between simple RT and

Table 4

Correlation Analysis of RTs for Experiment 2

\begin{tabular}{|c|c|c|c|}
\hline Subject & $\operatorname{corr}\left(\mathbf{R T}_{\mathrm{L}}, \mathbf{R T}_{\mathbf{R}}\right)$ & $\operatorname{corr}\left(R_{T}, R_{T} T_{L}-R T_{R}\right)$ & $\operatorname{corr}\left(\mathrm{RT}_{\mathrm{R}}, \mathrm{RT}_{\mathrm{R}}-\mathrm{RT}_{\mathrm{L}}\right)$ \\
\hline M.P. & $.96 / .97$ & $.12 / .02$ & $.17 / .24$ \\
\hline $\begin{array}{l}\text { T.H. } \\
\text { R.U. }\end{array}$ & $\begin{array}{l}.99 / .99 \\
.97 / .98\end{array}$ & $\begin{array}{c}.10 / .23 \\
-.19 /-.19\end{array}$ & $\frac{.07 /-.09}{.41 / .36}$ \\
\hline Mean & $.97 / .98$ & $.01 / .02$ & $.22 / .18$ \\
\hline $\begin{array}{l}\text { Mean Percentage of } \\
\text { Common Variance }\end{array}$ & $95 \% / 96 \%$ & $2 \% / 3 \%$ & $7 \% / 7 \%$ \\
\hline
\end{tabular}

Note-The number before (afier) the slash indicates the data for the soft (loud) condition. The underlined correlations do not differ significantly from zero $(\alpha=.05$, two-tailed $)$. 
RT difference obtained in Experiment 1 is also obtained in Experiment 2. The proportion of common variance, as shown by the average coefficient of determination in the bottom row of Table 4, is again very low. The coefficient of determination is again greater for the correlation of $\mathrm{RT}_{\mathrm{R}}$ and $\mathrm{RT}$ difference than for the correlation of $\mathrm{RT}_{\mathrm{L}}$ and RT difference. A surprising result is the reversal of these correlations for Subjects T.H. and R.U., as compared with Experiment 1.

Since, for Subjects T.H. and R.U., the results in both experiments show more different than common features, one might ask whether there exists a modality-independent motor path. It is remarkable, in this context, that in another double response study (Nakamura et al., 1975), a dependency of RT difference upon the specific experimental condition was also observed. Nakamura et al. required their subjects to respond by rapidly flexing their forearms bilaterally while the EMG onsets in the biceps muscles were recorded as indicators of RT. They measured RT difference under three conditions: response to a tone with a warning signal, response to a tone without a warning signal, and self-initiated double responses. The absolute mean RT difference depended upon the experimental condition, as did the size of the standard deviation.

\section{SUMMARY OF EMPIRICAL FINDINGS}

Several findings were obtained from the double response paradigm. These can be summarized in the following list:

(1) The estimated variance of the motor delay contributes only marginally to the whole RT variance. The estimates of the standard deviation of the motor delay range from 3 to $12 \mathrm{msec}$. These estimates agree fairly well with those obtained in finger-tapping experiments (Vorberg \& Hambuch, 1977; Wing \& Kristofferson, 1973).

(2) RT difference distribution is affected by stimulus intensity. This finding shows that stimulus intensity also affects very late stages in a simple RT task.

(3) There is an inverse relation between stimulus intensity and variance of RT difference. If one proceeds on the assumption that there is a positive relation between mean and variance of the motor delay, then mean motor delay decreases with increasing stimulus intensity. This conclusion contradicts the assumption that only the latency of early stages is speeded up by stimulus intensity (Nissen, 1977; Sternberg, 1969). However, this conclusion would be in agreement with the findings obtained by Hazelhoff and Wiersma (1926), Vogelsang (1925), and Roufs (1974), which were discussed in the introduction.

(4) Correlation analysis of simple RTs, and simple RTs with RT difference, revealed that the two components $S$ and $\mathrm{M}$ might correlate positively even within a constant intensity level. There is some evidence that the correlation between $S$ and $M$ increases with stimulus intensity. The correlation between $S$ and $M_{R}$ is probably greater than that between $S$ and $M_{L}$.

(5) Comparing the results of both experiments suggests that a modality-independent motor path probably does not exist.

\section{MODEL}

Meijers and Eijkman (1974; Meijers, Teulings, \& Eijkman, 1976) developed a stochastic model for isometric muscle contraction required in simple RT experiments. In this theoretical section, we will generalize their model. This generalized model predicts that with increasing stimulus intensity, mean and variance of the motor delay decrease.

Meijers and Eijkman proposed that $\mathrm{K}$ units (e.g., pyramidal tract neurons with corresponding motoneurons), operating independently and in parallel, must be active before a movement, say of the finger, is observed. Each impulse of an activated unit leads to a small contraction (twitch tension) of the supplied muscle fiber. If enough, say $K$, units started to fire, the summation of these individual twitch tensions is sufficient to initiate the required response. Meijers and Eijkman have shown an interesting property of their model in agreement with neurological results: Although the individual conduction times of the single units show a rather large variance, the motor delay until activation of the $K^{\text {th }}$ unit has only a small variation, predicting the excellent timing accuracy of the motor system.

We now extend the basic model, adding one assumption concerning the activation of a single unit itself. To be specific, we assume that the activation of a single unit also depends to some degree on stimulus intensity. It is reasonable to believe that the greater neural activity in the sensory system caused by greater intensity more efficiently excites a single unit in the motor system. Let $\mathrm{P}(\mathrm{I})$ be the probability that a single unit is activated after stimulus presentation. We state that $\mathrm{P}(\mathrm{I})$ increases monotonically with increasing stimulus intensity I.

\section{Assumptions}

(1) The total number of units to extend the muscle under investigation is $n$. The exact value of $n$ is unknown and therefore we will later vary $n$ to study the predictions.

(2) For the purpose of simplicity, we assume that every unit has the same probability $P(I)$ of activation after sensory processing of the stimulus. $K=(0,1, \ldots, n)$ is a random variable and represents the number of activated units in a single RT trial. Note that $K$ follows a binomial distribution with parameters $n, P(I)$.

(3) Let $\mathbf{T}$ denote the time from excitation until the production of a twitch tension for a single unit. For simplicity, we assume the same probability density $g(t)$ of $T$ for each unit. Meijers and Eijkman (1974) extracted such a probability distribution from a neurological study (Evarts, 1966) with monkeys. They found that $g(t)$ is approximated fairly well by a fourth-order gamma function with exponent $\mathrm{a}=.1 / \mathrm{msec}$ :

$$
f(t)=\frac{a^{4} t^{3} e^{-a t}}{3 !}
$$


We will use this particular probability density to demonstrate the predictions.

(4) Each of the K units operates in parallel and independently. There is physiological evidence for justification of this assumption at least at the level of motoneurons (Gilson \& Mills, 1941; Milner-Brown, Stein, \& Yemm, 1973; Shiavi \& Negin, 1975).

We number the units which successively cause single twitch tensions $1, \ldots, m, \ldots, K$. Now, if the $m^{\text {th }}$ twitch tension occurs, the summed force is sufficient for pressing of the response key. Let us denote the time elapsing between the central motor command and the $\mathrm{m}^{\text {th }}$ twitch tension as $\mathbf{M}_{\mathbf{m}}$ (the motor delay $\mathbf{M}$ ). From Assumptions 1 to 4 , the probability density of the motor delay $M_{m}$ was derived (cf. Appendix B):

$\mathbf{f}_{\mathbf{M}_{m}}(t)$

$$
=\frac{\overline{G(t)}\left[\frac{G(t)}{1-G(t)}\right]^{m}[1-P(I)]^{n} m \sum_{k=m}^{n}\left(\begin{array}{l}
k \\
m
\end{array}\right)\left(\begin{array}{l}
n \\
k
\end{array}\right)\left[\frac{P(I)(1-G(t))}{1-P(I)}\right]^{k}}{P(K \geq m)},
$$

where $G(t)$ denotes the distribution function of $T$. $P(K \geq m)$ is the probability that $m$ or more units are active. Under regular conditions, $P(K \geq m)$ converges rapidly to 1 as $n$ increases (cf. Appendix B).

\section{Predictions}

In Figure 3, different density functions, $f_{\mathbf{M}_{\mathbf{m}}}(t)$ according to Equation 9, have been depicted for the same values, $m=32$ and $n=64$, but for various $P(I) s$ together with $g(t)$. It can be seen that all $f_{M_{m}}(t)$ s show less variance than $g(t)$ and that the variance of the different $f_{M_{m}}$ (t)s decreases with increasing activation probabilities.

To study the predictions of the model in more detail, we calculated expectations and standard deviations of $\mathbf{M}_{\mathrm{m}}$ for different parameter values, $m, n$, and $P(I)$. In Figure 4 , these calculations are shown as a function of activation probability $\mathrm{P}(\mathrm{I})$. Each expectation, $\mathrm{E}(\mathrm{M} \mid \mathrm{n}, \mathrm{m})$, starts to the left at a $P(I)$ for which $P(K \geq m)$ is exactly

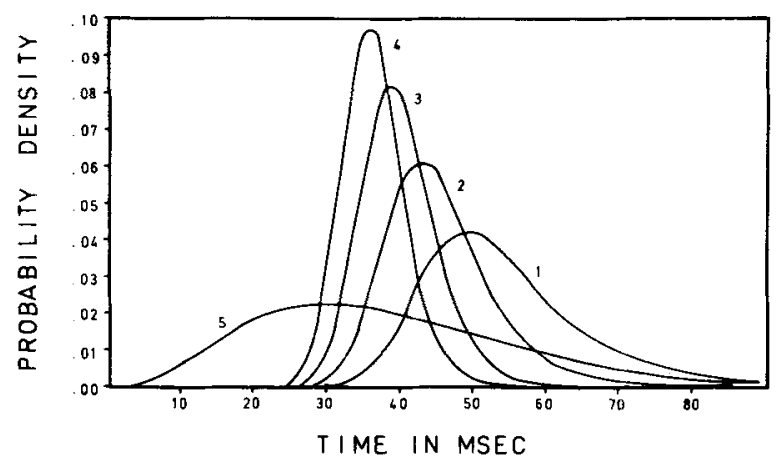

Figure 3. Different distributions of the motor delay $M_{m}(1-4)$. The parameters $m$ and $n$ are the same, only $P(I)$ varies. The values of $P(I)$ are $.7, .8, .9$, and 1 for distributions $1,2,3$, and 4 , respectively. The distribution for a single unit is 5 .

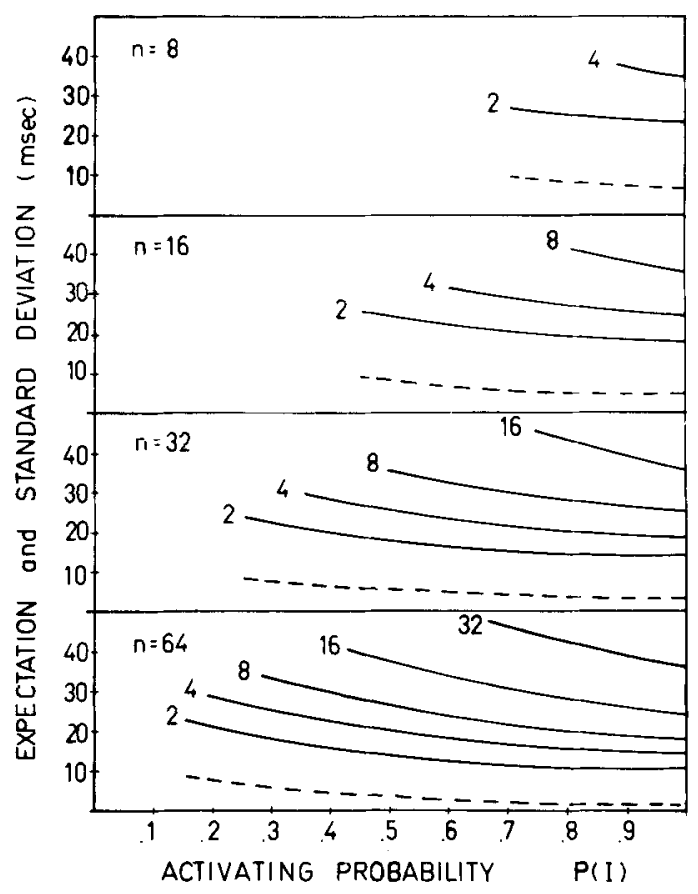

Figure 4. Expectations (-) and standard deviations (---) of motor delay $M_{m}$ for different values $m$ and $n$ as a function of activation probability. Each graph begins at an activation probability for which the corresponding $\mathbf{P}(K \geq m \mid n, P(I)$ is exactly .999 .

999. For example, the graph of $\mathrm{E}(\mathrm{M} \mid \mathrm{n}=32, \mathrm{~m}=8)$ starts at $P(I)=.5$, since $P(K \geq 8 \mid n=32, p=.5)$ is .999.

Several predictions can be gathered from Figure 4: (1) Standard deviations decrease with increasing $P(I)$ for all parameter values, mostly from 10 to $5 \mathrm{msec}$. It was found that standard deviations depend somewhat on $\mathrm{n}$ and to only a small extent on $\mathrm{m}$. Generally, standard deviations increase a little with $\mathrm{m}$ for fixed $\mathrm{n}$, but the differences are actually so small that we decided to plot an average standard deviation for each $\mathrm{n}$, to make the figure more clear. (2) Expectations depend on $m$ and $n$, decreasing with increasing $\mathbf{n}$ and/or decreasing $\mathbf{n}$. It is clear, of course, that the model can account for our results and further demonstrates that the motor process is speeded up as standard deviations of $\mathrm{M}$ decrease.

Wood's (1977) results concerning the motor time are also predicted. He computed means and standard deviations of the motor time for each quartile of the simple distribution separately. The smallest motor times are found for the first quartile and the longest for the fourth quartile. More important here, means and standard deviations of the motor time increased together. Also, EMG energy and movement acceleration decreased with increasing mean RT, indicating that more units had been activated on the average when a fast motor time resulted.

\section{CONCLUSIONS}

The twofold purpose of this study was (1) to determine whether stimulus intensity affects only sensory process- 
ing or also stages that follow, and (2) to provide a physiologically motivated stochastic basis for the regular results obtained in both experiments. It was found that the variance of the motor delay contributes only a little to the whole RT variance and, further, that increasing stimulus intensity decreased the motor delay variance, also indirectly indicating a speeding up of the motor delay.

A modification of Meijers and Eijkman's model was advanced, which predicted decreasing standard deviations of the motor delay with increasing stimulus intensity. In addition, the model predicts a positive dependence between mean and standard deviation of the motor delay, suggesting also that the motor process is speeded up as soon as intensity increases.

\section{REFERENCES}

AleChSIEFF, N. (1900). Reactionszeiten bei Durchgangsbeobachtungen. Philosophische Studien, 16, 1-60.

BARTLETT, N. R., \& WhITE, C. T. (1965). Synchronization error in attempts to move the hands simultaneously. Perception and Motor Skills, 20, 933-937.

Botwinick, J., \& Thompson, L. W. (1966). Premotor and motor components of reaction time. Journal of Experimental Psychology, 71, 9-15.

Burbeck, S. L., \& LuCE, R. D. (1982). Evidence from auditory simple reaction times for both change and level detectors. Perception \& Psychophysics, 32, 117-133.

Denier van der Gon, J. J., \& Thuring, J.Ph. (1965). The guiding of human writing movements. Kybernetik, 2, 145-148.

ELLIOTT, R. (1968). Simple visual and simple auditory reaction time: A comparison. Psychonomic Science, 10, 335-336.

EvarTs, E. V. (1966). Pyramidal tract activity associated with a conditioned hand movement in the monkey. Journal of Neurophysiology, 29, 1011-1027.

EXNER, S. (1875). Experimentelle Untersuchungen der einfachsten psychischen Prozesse-III. Pflügers Archiv für die gesamte Physiologie, 11, 403-589.

FröHLICH, F. W. (1929). Die Empfindungszeit. Jena: Gustav Fischer.

GiBBON, J., \& RUTSCHMANN, R. (1969). Temporal order judgement and reaction time. Science, $\mathbf{1 6 5}, 413-415$.

GiLson, A. S., \& MiLLS, W. B. (1941). Activities of single motor units in man during slight voluntary efforts. American Journal of Physiology, 133, 658-669.

GolDSTONE, S. (1968). Reaction time to onset and termination of lights and sounds. Perceptual \& Motor Skills, 27, 1023-1029.

Grice, G. R. (1968). Stimulus intensity and response evocation. Psychological Review, 75, 359-373.

HazelhofF, F. F., \& Wiersma, H. (1925a). Die Wahrnehmungszeit. 1. Artikel. Die Bestimmung der Schnelligkeit des Wahrnehmens von Lichtreizen nach der Lokalisationsmethode. Zeitschrift für Psychologie, 96, 171-188.

HAZElhoff, F. F., \& Wiersma, H. (1925b). Die Wahrnehmungszeit. 2. Artikel. Zeitschrift für Psychologie, 97, 174-190.

HAZELHOFF, F. F., \& Wiersma, H. (1926). Die Wahrnehmungszeit. 3. Artikel. Zeitschrift für Psychologie, 98, 366-377.

HILDRETH, J. D. (1979). Block's law and a poisson counting model for simple reaction time to light. Perception \& Psychophysics, 26, $153-162$.

KEndall, M. G., \& STUART, A. (1969). The advanced theory of statistics (Vol. 1, 3rd ed.). New York: Hafner.

KoHFELD, D. L. (1971). Simple reaction time as a function of stimulus intensity in decibels of light and sound. Journal of Experimental Psychology, 88, 251-257.

KOHFELD, D. L. (1982). Reaction-time scales of auditory intensity. Paper presented at the 23rd Annual Meeting of the Psychonomic Society, Minneapolis, Minnesota.

Kohfeld, D. L., Santee, J. L., \& Wallace, N. D. (1981). Loud- ness and reaction time: II. Identification of detection components at different intensities and frequencies. Perception \& Psychophysics, 29. 550-562.

KoRnBlum, S. (1973). Simple reaction times as a race between signal detection and time estimation: A paradigm and model. Perception \& Psychophysics, 13, 108-112.

LEVICK, W. R. (1973). Variation in the response latency of cat retinal ganglion cells. Vision Research, 13, 837-853

LuCE, R. D., \& GReEN, D. M. (1972). A neural timing theory for response times and the psychophysics of intensity. Psychological Review, 79, 14-57.

MCGILl, W. J. (1963). Stochastic latency mechanisms. In R. D. Luce, R. R. Bush, \& E. Galanter (Eds.), Handbook of mathematical psychology (Vol. 1). New York: Wiley.

MeIJers, L. M. M., \& EIJKMan, E. G. J. (1974). The motor system in simple reaction time experiments. Acta Psychologica, 38, 367-377.

MejJers, L. M. M., \& ElJKMan, E. G. J. (1977). Distributions of simple RT with single and double stimuli. Perception \& Psychophysics, 22, 41-48.

Meijers, L. M. M., Teulings, J.L.H.M., \& Eijkman, E. G. J. (1976). Model of the electromyographic activity during brief isometric contractions. Biological Cybernetics, 25, 7-16.

Milner-Brown, H. S., STein, R. B., \& Yemm, R. (1973). The contractile properties of human motor units during voluntary isometric contractions. Journal of Physiology (London), 228, 285-306.

Nakamura, R., \& Sarto, H. (1974). Preferred hand and reaction time in different movement patterns. Perceptual and Motor Skills, 39, $1275-1281$.

Nakamura, R., Taniguchi, R., \& Oshima, Y. (1975). Synchronization error in bilateral simultaneous flexion of elbows. Perceptual and Motor Skills, 40, 527-532.

Nissen, M. J. (1977). Stimulus intensity and information processing. Perception \& Psychophysics, 22, 338-352.

Posner, M. I. (1975). Psychobiology of attention. In M. Gazzaniga \& C. Blakemore (Eds.), Handbook of psychobiology. New York: Academic Press.

Roufs, J. A. J. (1974). Dynamic properties of vision-V: Perception lag and reaction time in relation to flicker and flash thresholds. $V i$ sion Research, 14, 853-869.

ShIAVI, R., \& NeGIN, M. (1975). Multivariate analysis of simultaneously active motor units in human skeletal muscle. Biological Cynbernetics, 20, 9-16,

STERNBERG, S. (1969). The discovery of processing stages: Extensions of Donders' method. In W. G. Koster (Ed.), Attention and performance II. Acta Psychologica, 30, 276-315.

Tond, J, W. (1912). Reaction to multiple stimuli. Archives of Psychotogy, Whole No. 25. (Monograph)

Vaughan, H. G., CostA, L. D., \& GILDEN, L. (1966). The functional relation of visual evoked response and reaction time to sitmulus intensity. Vision Research, 6, 645-656.

VoGELSANG, K. (1925). Über die Beziehung von Empfindungszeit und Reaktionszeit im Gebiete des Gesichtssinnes. Pflügers Archiv für die gesamte Physiologie, 208, 93-109.

VORBERG, D., \& HAMBUCH, R. (1977). On the temporal control of rhythmic performance. In Requin, J. (Ed.), Attention and Performance VII. New York: Academic Press.

Wing, A. M., \& Kristofferson, A. B. (1973). Response delays and the timing of discrete motor responses. Perception \& Psychophysics, 14, 5-12.

WooD, G. A. (1977). An electrophysiological model of human visual reaction time. Journal of Motor Behavior, 9, 267-274.

\section{APPENDIX A}

\section{Glossary}

Here we provide a list, with brief definitions, of main symbols used in the text and in the appendixes.

$\mathrm{RT}_{\mathrm{L}}$ Abbreviation for simple reaction time of the left hand. $\mathrm{RT}_{\mathrm{R}}$ Abbreviation for simple reaction time of the right hand. 
S Time needed to detect the stimulus and to prepare the motor command for movement execution (Figure 1).

$M_{L} \quad$ Motor delay of the left hand (Figure 1).

$M_{R}$ Motor delay of the right hand (Figure 1).

D Reaction time difference $D=R T_{L}-R T_{R}=M_{L}-M_{R}$.

$\mathrm{T}$ Time delay of a single unit (e.g., pyramidal tract neuron with corresponding motoneurons) from excitation to the production of a twitch tension.

$\mathbf{M}_{\mathrm{m}}$ Time elapsing between the central motor command and the occurrence of the $\mathrm{m}^{\text {th }}$ twitch tension.

P(I) Activation probability of a single unit. $P(I)$ increases monotonically with increasing stimulus intensity $I$.

$g(t)$ The density function of the random variable $T$.

$\mathrm{K}$ The number of activated units.

\section{Basic Expressions}

In this section, we list the basic expressions used for the relations $R_{T}=S+M_{L}$ and $R T_{R}=S+M_{R}$. We refer occasionally to these basic expressions when deriving, in Appendix $A$, the equations appearing in the text.

The basic expressions can be derived in a straight-forward fashion by using the distributive property of covariances, and by noting that the covariance of a random variable by itself equals its variance, that is, $\operatorname{cov}(X, X)=\operatorname{var}(X)$ :

Let $X=s \cdot A+t \cdot B$ and $Y=v \cdot C+w \cdot D$, where $A, B, C$, and $D$ are random variables and $s, t, v$, and $w$ are arbitrary constants. Then

$$
\begin{aligned}
\operatorname{cov}(X, Y)= & \operatorname{cov}(s \cdot A+t \cdot B, v \cdot C+w \cdot D) \\
= & s v \cdot \operatorname{cov}(A, C)+s w \cdot \operatorname{cov}(A, D) \\
& +t v \cdot \operatorname{cov}(B, C)+t w \cdot \operatorname{cov}(B, D) .
\end{aligned}
$$

Consider the derivation of the covariance between $\mathrm{RT}_{\mathrm{L}}$ and $\mathrm{RT}$ difference $\mathrm{RT}_{\mathrm{L}}-\mathrm{RT}_{\mathrm{R}}$ :

$$
\begin{aligned}
\operatorname{cov}\left(R_{T}, R_{L}-R_{L}\right)= & \operatorname{cov}\left(S+M_{L}, M_{L}-M_{R}\right) \\
= & \operatorname{cov}\left(S, M_{L}\right)-\operatorname{cov}\left(S, M_{R}\right) \\
& +\operatorname{var}\left(M_{L}\right)-\operatorname{cov}\left(M_{L}, M_{R}\right)
\end{aligned}
$$

In the same way, the following five basic expressions can be derived:

$$
\begin{aligned}
\operatorname{cov}\left(R_{T}, R_{R}-R_{R}\right)= & \operatorname{cov}\left(S, M_{R}\right)-\operatorname{cov}\left(S, M_{L}\right) \\
& +\operatorname{var}\left(M_{R}\right)-\operatorname{cov}\left(M_{L}, M_{R}\right)
\end{aligned}
$$

$$
\begin{aligned}
& \operatorname{cov}\left(\mathbf{R T}_{\mathbf{L}}, \mathrm{RT}_{\mathbf{R}}\right) \\
& =\operatorname{var}(\mathbf{S})+\operatorname{cov}\left(\mathbf{S}, \mathbf{M}_{\mathbf{R}}\right)+\operatorname{cov}\left(\mathbf{S}, \mathbf{M}_{\mathbf{L}}\right)+\operatorname{cov}\left(\mathbf{M}_{\mathbf{L}}, \mathbf{M}_{\mathbf{R}}\right)
\end{aligned}
$$

$$
\begin{aligned}
& \operatorname{var}\left(\mathrm{RT}_{\mathrm{L}}\right)=\operatorname{var}(\mathrm{S})+\operatorname{var}\left(\mathrm{M}_{\mathbf{L}}\right)+2 \cdot \operatorname{cov}\left(\mathrm{S}, \mathrm{M}_{\mathrm{L}}\right) \\
& \operatorname{var}\left(\mathrm{RT}_{\mathbf{R}}\right)=\operatorname{var}(\mathrm{S})+\operatorname{var}\left(\mathrm{M}_{\mathbf{R}}\right)+2 \cdot \operatorname{cov}\left(\mathbf{S}, \mathbf{M}_{\mathbf{R}}\right)
\end{aligned}
$$

$\operatorname{var}\left(\mathbf{R T}_{\mathbf{L}}-\mathbf{R T}_{\mathbf{R}}\right)=\operatorname{var}\left(\mathrm{M}_{\mathbf{L}}\right)+\operatorname{var}\left(\mathbf{M}_{\mathbf{R}}\right)-2 \cdot \operatorname{cov}\left(\mathbf{M}_{\mathbf{L}}, \mathbf{M}_{\mathbf{R}}\right)$.

\section{Correlation Between $\mathbf{R T}_{\mathbf{L}}$ and $\mathbf{R T}_{\mathbf{R}}$}

The product moment correlation between $R_{L}$ and $R T_{R}$ is given by

$$
\operatorname{corr}\left(R_{L}, R_{R}\right)=\frac{\operatorname{cov}\left(R T_{L}, R_{R}\right)}{S D\left(R T_{L}\right) S D\left(R T_{R}\right)}
$$

To obtain Equation 6, which appeared in the text, one has to substitute Basic Expressions 3A, 4A, and $5 \mathrm{~A}$ for $\operatorname{cov}\left(\mathrm{RT}_{\mathrm{L}}, \mathrm{RT}_{\mathrm{R}}\right)$, $\mathrm{SD}\left(\mathrm{RT}_{\mathrm{L}}\right)$, and $\mathrm{SD}\left(\mathrm{RT}_{\mathrm{R}}\right)$, respectively.

\section{Correlation Between Simple RT and RT Difference}

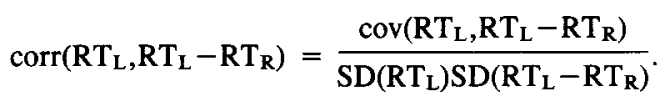

Substituting the Basic Expressions 1A, 4A, and 6A, one arrives at Equation 8a. The correlation $\operatorname{corr}\left(\mathrm{RT}_{\mathrm{L}}, \mathrm{RT}_{\mathrm{L}}-\mathrm{RT} \mathrm{T}_{\mathrm{R}}\right)$ is derived in an analogous fashion.

Variance Ratio var(S)/var(M). To derive Equation 4, which appeared in the text, we first introduce two averages: $\operatorname{var}(\mathrm{M})$ $=\left[\operatorname{var}\left(\mathbf{M}_{\mathbf{L}}\right)+\operatorname{var}\left(\mathbf{M}_{\mathbf{R}}\right)\right] / 2$ and $\operatorname{cov}(\mathbf{S}, \mathbf{M})=\left[\operatorname{cov}\left(\mathbf{S}, \mathrm{M}_{\mathrm{L}}\right)+\right.$ $\left.\operatorname{cov}\left(S, M_{R}\right)\right] / 2$. Thus, Basic Expression $6 \mathrm{~A}$ can also be written as

$$
\operatorname{var}\left(\mathbf{R T}_{\mathbf{L}}-\mathbf{R T}_{\mathbf{R}}\right)=2 \cdot \operatorname{var}(\mathbf{M})-2 \cdot \operatorname{cov}\left(\mathbf{M}_{\mathbf{L}}, \mathbf{M}_{\mathbf{R}}\right)
$$

Rearranging, we have

$$
2 \cdot \operatorname{var}(\mathbf{M})=\operatorname{var}\left(R_{T_{L}}-R_{T}\right)+2 \cdot \operatorname{cov}\left(M_{L}, M_{R}\right)
$$

Now we add Basic Expressions 4A and 5A, thereby substituting the introduced averages. The result is

$$
\operatorname{var}\left(R_{T_{L}}\right)+\operatorname{var}\left(R_{R}\right)=2 \cdot \operatorname{var}(S)+2 \cdot \operatorname{var}(\mathrm{M})+4 \cdot \operatorname{cov}(S, M)
$$

Substituting Equation 7A and rearranging yields

$$
\begin{gathered}
2 \cdot \operatorname{var}(S)=\operatorname{var}\left(R_{T_{L}}\right)+\operatorname{var}\left(R_{R}\right)-\operatorname{var}\left(R T_{L}-R_{R}\right) \\
-2 \cdot \operatorname{cov}\left(M_{L}, M_{R}\right)-4 \cdot \operatorname{cov}(S, M) .
\end{gathered}
$$

Dividing Equation $8 \mathrm{~A}$ by Equation $7 \mathrm{~A}$, one obtains the desired variance ratio $\operatorname{var}(\mathrm{S}) / \mathrm{var}(\mathrm{M})$, which appears as Equation 4 in the text.

\section{APPENDIX B}

\section{Probability Density of $\mathbf{M}_{\mathrm{m}}$}

If $\mathrm{k} \in \mathrm{K}$ units are activated, the conditional probability density $f_{M_{m}}\left(t \mid K=k\right.$ ) is given by the $m^{\text {th }}$ order statistic $M_{m}$ (the time elapsing from the central motor command until the occurrence of the $\mathrm{m}^{\text {th }}$ twitch tension):

$$
f_{M_{m}}(t \mid K=k)
$$

$$
=g(t) \frac{k !}{(k-m) !(m-1) !}[G(t)]^{m-1}[1-G(t)]^{k-m},
$$


and the probability of $\mathrm{k}$ activated units from a total of $\mathrm{n}$ is:

$$
P(K=k)=\left(\begin{array}{l}
n \\
k
\end{array}\right) P^{k}(1-P)^{n-k} .
$$

By conditioning on $\mathrm{K}$, we see

$$
f_{M_{m}}(t \mid K \geq m)=\frac{\sum_{k=m}^{n} f_{M_{m}}(t \mid K=k) P(K=k)}{P(K \geq m)} .
$$

Inserting the above expressions for $f_{M_{m}}(t \mid K \geq m)$ and $P(K=k)$, we get at Equation 9.

\section{Converge to one of $P(K \geq m)$}

At first we approximate the desired proability

$$
P(K \geq m)=\sum_{k=m}^{n}\left(\begin{array}{l}
n \\
k
\end{array}\right) P^{k}(1-P)^{n-k}
$$

by the normal distribution function

$$
\begin{aligned}
\mathrm{P}(\mathrm{K} \geq \mathrm{m}) & =1-\phi\left[\frac{\mathrm{m}-\mathrm{nP}}{\sqrt{\mathrm{nP}(1-\mathrm{P})}}\right] \\
& =1-\phi\left[\frac{\mathrm{m} / \mathrm{n}-\mathrm{P}}{\sqrt{\mathrm{P}(1-\mathrm{P})}} \sqrt{\mathrm{n}}\right] .
\end{aligned}
$$

Now we can see that if $n$ becomes large and the ratio $m / n$ is less than the activation probability $P$, the second term on the right side becomes zero and therefore $\mathrm{P}(\mathrm{K} \geq \mathrm{m})$ attains one. To see how fast $P(K \geq m)$ reaches one, consider the following parameters: $\mathrm{n}=100, \mathrm{p}=.8, \mathrm{~m}=50$, for which we computed $\mathrm{P}(\mathrm{K} \geq \mathrm{m})=.999999750$. So, the probability that a muscle contraction follows after a central command is practically 1 , although a single unit is activated only with probability .8 .

Some readers might find an alternative activation model more plausible, one for which a muscle contraction follows a central motor command with probability 1: Some units are always activated $(P=1)$ by a central motor command, and they are sufficient for initiating the desired movements. Some of the remaining units are activated only from trial to trial $(P<1)$. In this more realistic case, the number of activated units $\mathrm{K}$ follows a generalized binomial distribution (Kendall \& Stuart, 1969, Section 5.10). However, if $\overline{\mathrm{P}}$ is the average of the single activation probabilities, then $P(K=k)$ is usually very much like the binominal distribution $\left(\begin{array}{l}\mathbf{k} \\ \mathbf{k}\end{array}\right) \overline{\mathrm{P}}^{\mathbf{k}}(1-\overline{\mathrm{P}})^{\mathbf{n}-\mathbf{k}}$. So, if we think of $\mathrm{P}(\mathrm{l})$ in Equation 9 as an average activation probability, our general conclusions are still valid.

(Manuscript received July 6, 1983;

revision accepted for publication September 18,1984 .) 